\title{
Reversal of Age-Related Alterations in Synaptic Plasticity by Blockade of L-Type $\mathrm{Ca}^{2+}$ Channels
}

\author{
Christopher M. Norris, ${ }^{1}$ Shelley Halpain, ${ }^{2}$ and Thomas C. Foster ${ }^{1}$ \\ ${ }^{1}$ Department of Psychology and the Neurosciences Graduate Program, University of Virginia, Charlottesville, Virginia \\ 22903, and 2Department of Cell Biology, The Scripps Research Institute, La Jolla, California 92037
}

The role of L-type $\mathrm{Ca}^{2+}$ channels in the induction of synaptic plasticity in hippocampal slices of aged (22-24 months) and young adult (4-6 months) male Fischer 344 rats was investigated. Prolonged $1 \mathrm{~Hz}$ stimulation (900 pulses) of Schaffer collaterals, which normally depresses CA3/CA1 synaptic strength in aged rat slices, failed to induce long-term depression (LTD) during bath application of the L-channel antagonist nifedipine $(10 \mu \mathrm{M})$. When $5 \mathrm{~Hz}$ stimulation (900 pulses) was used to modify synaptic strength, nifedipine facilitated synaptic enhancement in slices from aged, but not young, adult rats. This enhancement was pathway-specific, reversible, and impaired by the NMDA receptor (NMDAR) antagonist DL-2-amino5-phosphonopentanoic acid (AP5). Induction of long-term potentiation (LTP) in aged rats, using $100 \mathrm{~Hz}$ stimulation, occluded subsequent synaptic enhancement by $5 \mathrm{~Hz}$ stimulation, sug- gesting that nifedipine-facilitated enhancement shares mechanisms in common with conventional LTP. Facilitation of synaptic enhancement by nifedipine likely was attributable to a reduction $(\sim 30 \%)$ in the $\mathrm{Ca}^{2+}$-dependent $\mathrm{K}^{+}$-mediated afterhyperpolarization (AHP), because the $\mathrm{K}^{+}$channel blocker apamin $(1 \mu \mathrm{M})$ similarly reduced the AHP and promoted synaptic enhancement by $5 \mathrm{~Hz}$ stimulation. In contrast, apamin did not block LTD induction using $1 \mathrm{~Hz}$ stimulation, suggesting that, in aged rats, the AHP does not influence LTD and LTP induction in a similar way. The results indicate that, during aging, L-channels can (1) facilitate LTD induction during low rates of synaptic activity and (2) impair LTP induction during higher levels of synaptic activation via an increase in the $\mathrm{Ca}^{2+}$-dependent AHP.

Key Words: long-term depression; long-term potentiation; afterhyperpolarization; aging; hippocampus; Fischer 344
Long-term potentiation (LTP) and long-term depression (LTD) are $\mathrm{Ca}^{2+}$-dependent modifications in synaptic efficacy thought to underlie learning and memory processes (Bliss and Collingridge, 1993). During old age, when memory function declines, hippocampal synapses exhibit alterations in $\mathrm{Ca}^{2+}$-dependent synaptic plasticity (Foster and Norris, 1997). In particular, the threshold for LTP induction is increased (Deupree et al., 1993; Moore et al., 1993; Rosenzweig et al., 1997), and the decay of LTP is accelerated in aged rats (Barnes and McNaughton, 1980; deToledo-Morrell et al., 1988). Conversely, susceptibility to the induction of LTD is enhanced during aging (Norris et al., 1996; Foster and Norris, 1997). Although these age-related changes in $\mathrm{Ca}^{2+}$-dependent plasticity have been well characterized, much less is known about the mechanisms that generate these changes.

Mounting evidence indicates that $\mathrm{Ca}^{2+}$ influx through L-type voltage-dependent $\mathrm{Ca}^{2+}$ channels is elevated in CA1 neurons during aging (Pitler and Landfield, 1990; Moyer and Disterhoft, 1994; Campbell et al., 1996; Thibault and Landfield, 1996). We have speculated that a modest increase in $\mathrm{Ca}^{2+}$ influx through L-channels can raise and lower the thresholds for the induction of LTP and LTD, respectively (Foster and Norris, 1997). The level of postsynaptic $\mathrm{Ca}^{2+}$ achieved during synaptic activation appears to play a pivotal role in determining the direction and extent of

\footnotetext{
Received Dec. 24, 1997; revised Feb. 12, 1998; accepted Feb. 17, 1998.

This work was supported by the Commonwealth of Virginia Alzheimer's and Related Diseases Research Award Fund (to T.C.F.) and Grants from the National Institute of Mental Health (MH50861 to S.H.), the National Institute on Aging (AG14979 to T.C.F. and AG14549 to S.H.), and a Glenn Foundation/American Federation for Aging Research award (to C.M.N.).

Correspondence should be addressed to Dr. Thomas C. Foster, Department of Psychology, University of Virginia, Charlottesville, VA 22903.

Copyright (C) 1998 Society for Neuroscience $\quad 0270-6474 / 98 / 183171-09 \$ 05.00 / 0$
}

synaptic modification such that, in aged animals, an increased influx of $\mathrm{Ca}^{2+}$ during low-frequency synaptic activation would increase the susceptibility to LTD. In contrast, as the frequency of synaptic activation increases, $\mathrm{Ca}^{2+}$ influx through L-channels may impair LTP induction via activation of the $\mathrm{Ca}^{2+}$-dependent $\mathrm{K}^{+}$-mediated afterhyperpolarization (AHP), which is augmented in aged mammals (Landfield and Pitler, 1984; Moyer et al., 1992). Previous research demonstrates that a large AHP can reduce the integration of high-frequency synaptic events by shunting synaptic depolarization, thus impairing NMDA receptor (NMDAR)mediated processes such as LTP (Sah and Bekkers, 1996). As such, age-related changes in $\mathrm{Ca}^{2+}$ influx through L-channels may contribute to alterations in LTP and LTD.

The current research explored the influence of L-channels on the induction of CA3/CA1 synaptic plasticity during aging. The results demonstrated that, in aged rat slices, the L-channel antagonist nifedipine reverses the susceptibility to induction of LTD using $1 \mathrm{~Hz}$ stimulation and enhances the induction of NMDARdependent synaptic enhancement using $5 \mathrm{~Hz}$ stimulation. The facilitation of synaptic enhancement during L-channel blockade was explained best by a reduction of the AHP by nifedipine, because apamin, which reduces the AHP via direct blockade of $\mathrm{K}^{+}$channels, also promoted enhancement but did not prevent LTD in slices from aged rats. The results provide a direct link between increased L-channel-mediated $\mathrm{Ca}^{2+}$ influx and altered $\mathrm{Ca}^{2+}$-dependent synaptic plasticity during aging.

Parts of this paper have been published in abstract form (Norris et al., 1997).

\section{MATERIALS AND METHODS}

Transverse hippocampal slices were harvested from aged (22-24 months) and young adult (4-6 months) male Fischer 344 rats, as previously 
described (Norris et al., 1996). Briefly, slices initially were prepared in ice-cold artificial CSF (ACSF) containing a reduced $\mathrm{CaCl}_{2}$ concentration $(0.5 \mathrm{mM})$. Slices then were transferred to an interface recording chamber where they were perfused with oxygenated ACSF, which contained (in mM) $124 \mathrm{NaCl}, 2 \mathrm{KCl}, 1.25 \mathrm{KH}_{2} \mathrm{PO}_{4}, 2 \mathrm{MgSO}_{4}, 2 \mathrm{CaCl}_{2}, 26$ $\mathrm{NaHCO}_{3}$, and 10 dextrose, $\mathrm{pH} \sim 7.4$. Slices were maintained in a holding chamber $\left(23^{\circ} \mathrm{C}\right)$ and transferred to an interface recording chamber $\left(30^{\circ} \mathrm{C}\right)$ as needed.

Methods for collecting extracellular CA3/CA1 synaptic responses were identical to those used in Norris et al. (1996). Schaffer collaterals were activated with a bipolar stimulating electrode located in stratum radiatum of area CA1 at or near the CA3 border. For certain experiments a second stimulating electrode was placed in stratum radiatum near the subiculum and used to evoke responses in a control pathway that did not receive pattern stimulation. The recording electrode, a glass micropipette (1-6 M $\Omega$ ) filled with ACSF, was positioned in stratum radiatum of CA1, $\sim 1 \mathrm{~mm}$ away from the point of stimulation. Baseline stimulation consisted of $100 \mu \mathrm{sec}$ diphasic, constant current pulses delivered once every $30 \mathrm{sec}$ at an intensity sufficient to elicit an EPSP of $\sim 1 \mathrm{mV}$. Slope magnitude was calculated as the difference between two cursors, separated by $1 \mathrm{msec}$, and placed on the middle portion of the descending phase of the EPSP. Because stimulation was set to evoke a $1 \mathrm{mV}$ response, no age differences for baseline EPSP slope were observed. In some experiments nifedipine (Research Biochemicals, Natick, MA), DL-2-amino-5-phosphonopentanoic acid (AP5; Sigma, St. Louis, MO), or apamin (Sigma) was added to the slice perfusion medium at least $30 \mathrm{~min}$ before the delivery of patterned stimulation. All drugs were dissolved in distilled $\mathrm{H}_{2} \mathrm{O}$, except nifedipine (which was dissolved in DMSO), and stored as frozen stocks. Because of the light sensitivity of nifedipine, all experiments were conducted in a darkened room. To wash nifedipine from the perfusion medium, we reintroduced normal "drug-free" buffer to the slices and turned on the lights to facilitate inactivation of the compound.

Synaptic modification was induced by delivering 900 pulses to Schaffer collaterals at either 1 or $5 \mathrm{~Hz}$. Induction of LTP was achieved in some experiments by using two $1 \mathrm{sec}$ duration bursts of $100 \mathrm{~Hz}$ stimulation, each burst separated by $10 \mathrm{sec}$. Pattern stimulation was delivered at baseline stimulation intensity, and stimulus timing was controlled by a computer.

To quantify changes in synaptic strength after pattern stimulation, we collected 10 responses at various times after the induction of synaptic modification and normalized them to the average of the $10 \mathrm{~min}$ baseline immediately preceding pattern stimulation. Changes in synaptic strength are expressed as a percentage of baseline. Then the 10 normalized responses were averaged, and repeated measures ANOVA was applied to the means to determine differences across pattern stimulation sessions. Post hoc analyses were conducted with Scheffé's $F$ tests, with significance set at $p<0.05$. For illustration purposes, the two EPSP slope values collected per minute from an individual slice were averaged, and these points then were averaged across slices. Where stated, $n$ represents the number of slices used in each experiment. However, because an individual rat usually contributed one slice, and at the most two slices, to any given data set, $n$ also closely approximates the number of animals used.

Intracellular recordings were obtained from CA1 cells by using sharp microelectrodes $(50-100 \mathrm{M} \Omega$ ) filled with $3 \mathrm{M}$ potassium acetate. Only cells with a resting membrane potential less than $-60 \mathrm{mV}$, an input resistance $>20 \mathrm{M} \Omega$, and a $\mathrm{Na}^{+}$spike amplitude $>70 \mathrm{mV}$ were included in data analysis. Depolarizing current pulses (100 msec, $0.5-1.7 \mathrm{nA})$ were delivered through the intracellular electrode to elicit $\mathrm{Na}^{+}$spike bursts of five to seven spikes. The AHP was measured as the difference between the mean membrane potential during the $100 \mathrm{msec}$ period immediately before the onset of the depolarizing current and the mean membrane potential during the $800 \mathrm{msec}$ immediately after the offset of the depolarizing current. Changes in the AHP with drug application were calculated by comparing the average AHP from five successive responses collected before drug wash-in with the average of five successive responses collected 10-15 min after wash-in. Cells were current-clamped to a membrane potential between -65 and $-71 \mathrm{mV}$. In other experiments the NMDAR-mediated component of CA3/CA1 synaptic transmission was isolated by lowering the extracellular $\left[\mathrm{MgSO}_{4}\right]$ to $0.5 \mathrm{~mm}$ and by adding 20-60 $\mu \mathrm{M}$ 6,7-dinitroquinoxaline-2,3-dione (DNQX; Research Biochemicals) and $10 \mu \mathrm{M}$ picrotoxin (Sigma) to the perfusion medium. In these cases the intracellular EPSP magnitude was measured as the area above baseline.

\section{RESULTS}

\section{Induction of LTD in slices from aged rats exhibits sensitivity to L-channel blockade}

In control slices from aged rats, $1 \mathrm{~Hz}$ stimulation (900 pulses) produced a marked depression of the synaptic response (Fig. $1 A$ ). Synaptic strength after induction of LTD under these conditions was $72 \pm 4 \%$ of baseline $(p<0.05 ; n=3)$, a magnitude that is similar to that reported previously (Norris et al., 1996; Foster and Norris, 1997). To examine the role of L-type voltage-dependent $\mathrm{Ca}^{2+}$ channels in regulating the induction of LTD in slices from aged rats, we applied the L-channel antagonist nifedipine $(10 \mu \mathrm{M})$ to the slice perfusion medium. A train of $1 \mathrm{~Hz}$ stimulation, which typically produces robust LTD in aged animals, failed to induce LTD when it was delivered in the presence of nifedipine (106 \pm $7 \%$ of the initial baseline, $n=8$ ) and instead produced a slight, but insignificant, enhancement of the synaptic response (Fig. $\left.1 B_{1}, B_{2}\right)$. The EPSP of control pathways, after the $1 \mathrm{~Hz}$ train, also was unchanged (102 $\pm 6 \%, n=3$; data not shown), indicating that blockade of LTD by nifedipine was not attributable to a counteractive increase in the synaptic response during nifedipine application. After a $30 \mathrm{~min}$ period in which nifedipine was washed from the recording chamber, a subsequent episode of $1 \mathrm{~Hz}$ stimulation was delivered to these same slices in drug-free medium (Fig. $1 B_{3}$ ). Under these conditions $1 \mathrm{~Hz}$ stimulation significantly depressed the synaptic response relative to the baseline collected during the washout period $(83 \pm 5 \%, n=7 ; p<0.05)$. The results suggest that the induction of LTD in aged animals depends on the function of L-channels.

\section{Nifedipine facilitates the induction of synaptic enhancement in slices from aged rats}

In adults, stimulation at $5 \mathrm{~Hz}$ results in transient alterations in synaptic transmission (Landfield et al., 1986) but does not induce LTP or LTD at naive synapses. However, this same stimulation reliably induces depotentiation (i.e., reversal of LTP) if it is delivered soon after LTP induction (Staubli and Lynch, 1990; O'Dell and Kandel, 1994). Figure $2 A$ illustrates that, in normal medium, an episode of $5 \mathrm{~Hz}$ stimulation (900 pulses) produced only an initial short-lasting ( $\sim 10 \mathrm{~min})$ depression in slices from young adult and aged rats. Such short-lived depression is a typical outcome of long-duration 1-10 Hz stimulus trains (Mulkey and Malenka, 1992; O’Dell and Kandel, 1994; Mayford et al., 1995) and likely is attributable to a transient reduction in transmitter release. However, at $30 \mathrm{~min}$ after the $5 \mathrm{~Hz}$ train, the EPSP for both young adult $(n=6)$ and aged $(n=5)$ rat slices was not different from the initial baseline magnitude (young adult, $100 \pm$ $8 \%$; aged, $97 \pm 7 \%$ ). Similarly, $5 \mathrm{~Hz}$ stimulation, delivered in the presence of $10 \mu \mathrm{M}$ nifedipine, did not produce long-term alterations in synaptic strength in slices $(n=7)$ from the young adult group $(92 \pm 6 \%)$. In contrast to these findings, $5 \mathrm{~Hz}$ stimulation during L-channel blockade resulted in a slow-developing, but pronounced and pathway-specific, enhancement of transmission in aged rat slices (144 $\pm 8 \%$ in the test pathway, $n=16, p<$ 0.0001 ; and $98 \pm 5 \%$ in the control pathway, $n=14$ ) (Fig. $2 B_{1}$ ). In four of the slices illustrated in Figure $2 B_{1}$, nifedipine was washed from the recording medium, and a second round of $5 \mathrm{~Hz}$ stimulation was delivered $30 \mathrm{~min}$ later (Fig. $2 B_{2}$ ). After drug washout the enhanced response measured $25-30 \mathrm{~min}$ after the initial $5 \mathrm{~Hz}$ stimulation was depressed by this second $5 \mathrm{~Hz}$ stimulus train $(86 \pm 4 \% ; p<0.05)$. An additional $5 \mathrm{~Hz}$ train in the continued presence of nifedipine did not alter the magnitude 
$\mathbf{A}$

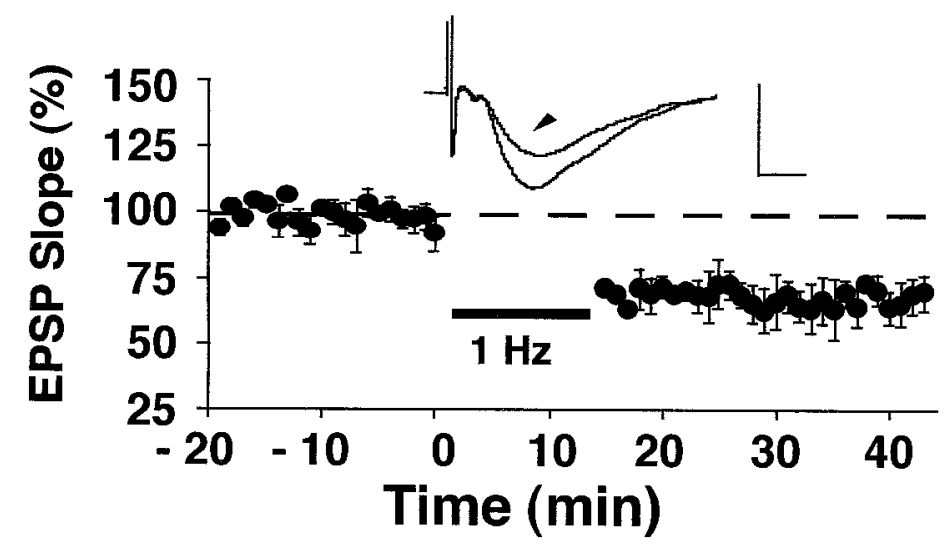

$B_{1}$

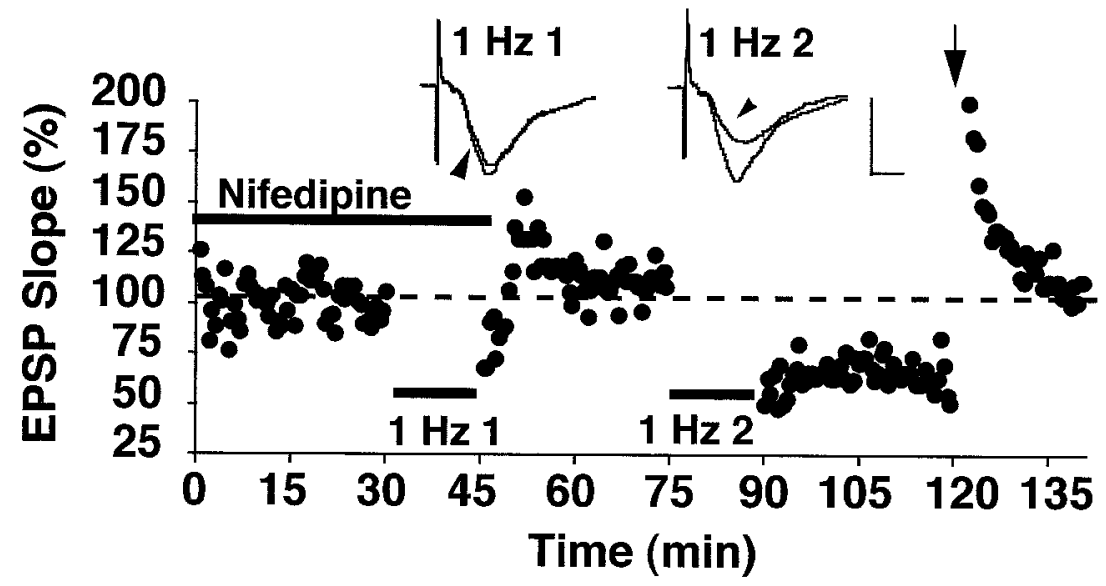

$\mathrm{B}_{2}$

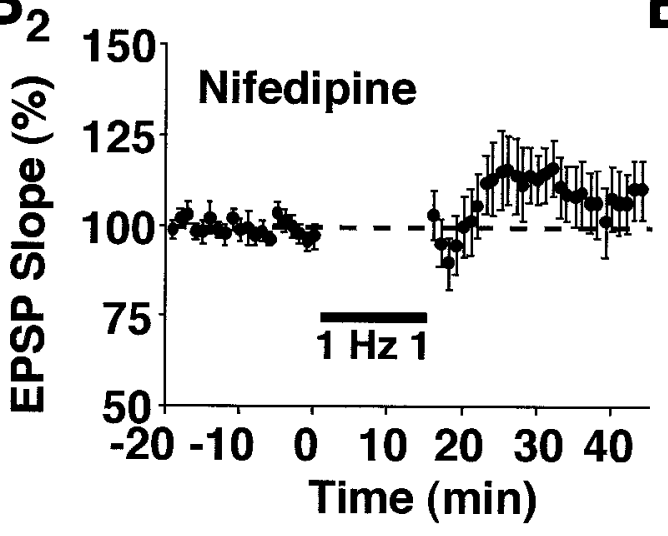

$\mathrm{B}_{3}$

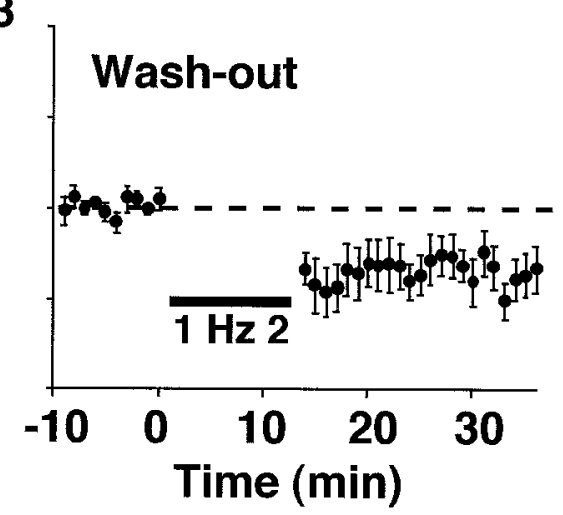

Figure 1. Nifedipine blocks the induction of LTD in aged rat slices. $A$, Plot of normalized field CA3/CA1 EPSP slopes (percentage of baseline \pm SEM) obtained in stratum radiatum from three slices in response to stimulation of Schaffer collateral fibers $(0.033 \mathrm{~Hz})$. After an initial baseline period, 900 pulses of continuous $1 \mathrm{~Hz}$ stimulation (bar) induced a significant depression of the synaptic response. $B_{1}$, An experiment conducted on an individual slice from an aged rat in which $1 \mathrm{~Hz}$ stimulation $(1 \mathrm{~Hz}$ 1) was delivered in the presence of $10 \mu \mathrm{M}$ nifedipine (thick bar) and did not depress the synaptic response. After the first $1 \mathrm{~Hz}$ train, nifedipine was washed from the recording medium, and a second episode of $1 \mathrm{~Hz}$ stimulation $(1 \mathrm{~Hz} 2)$ was delivered in a drug-free medium. This second train of $1 \mathrm{~Hz}$ stimulation induced a marked depression that could be reversed to baseline by $100 \mathrm{~Hz}$ stimulus bursts (arrow). Insets for $A$ and $B_{1}$ display the averaged field EPSP waveforms from 10 successive responses collected immediately before and $30 \mathrm{~min}$ after (arrowheads) the delivery of $1 \mathrm{~Hz}$ stimulation. Calibration: $1 \mathrm{mV}, 5 \mathrm{msec} . B_{2}, B_{3}$, Average data from aged rat slices $\left(B_{2}, n=8 ; B_{3}\right.$, $n=7$ ) that were treated identically to the individual case in $B_{1}$. Note that responses in $B_{3}$ are normalized to the average of responses in $B_{2}$ collected between 25 and 30 min after the termination of the first $1 \mathrm{~Hz}$ train. of initial enhancement (106 $\pm 6 \%, n=3$; data not shown), indicating that depression, or reversal of the potentiated response, was specific to L-channel function and not to a priming effect by the first episode of $5 \mathrm{~Hz}$ stimulation. Thus, in aged rat slices the direction of synaptic plasticity and the susceptibility to synaptic modification depend on the stimulation frequency, the activity of L-channels, and the recent history of the synapse (potentiated vs naive).

Nifedipine-facilitated enhancement in slices from aged rats is mechanistically similar to LTP induced by highfrequency stimulation

The pathway specificity and the reversible nature of nifedipinefacilitated enhancement are reminiscent of LTP. However, unlike nifedipine-facilitated enhancement, LTP typically is induced by short bursts of high-frequency stimulation (i.e., $100 \mathrm{~Hz}$ for $1 \mathrm{sec}$ ) and has a rapid onset. Thus, occlusion experiments were conducted to examine whether the increase in synaptic strength after $5 \mathrm{~Hz}$ stimulation during L-channel blockade is mechanistically similar to LTP induced by $100 \mathrm{~Hz}$ stimulation. In slices from aged rats, nifedipine was applied to the recording medium, and synaptic enhancement $(159 \pm 18 \%, n=3)$ was induced in one population of synapses (S1), using $5 \mathrm{~Hz}$ stimulation (Fig. $3 A$ ). After washout of the drug, two bursts of $100 \mathrm{~Hz}$ stimulation were delivered $30 \mathrm{~min}$ later to the potentiated synapses of S1 and produced a further increase in the EPSP $(119 \pm 9 \%$ of the post- 5 $\mathrm{Hz}$ baseline) that was considerably smaller than potentiation observed at naive synapses in the same slice (147 $\pm 11 \%$ in S2). This suggests that, although $5 \mathrm{~Hz}$ stimulation during L-channel 


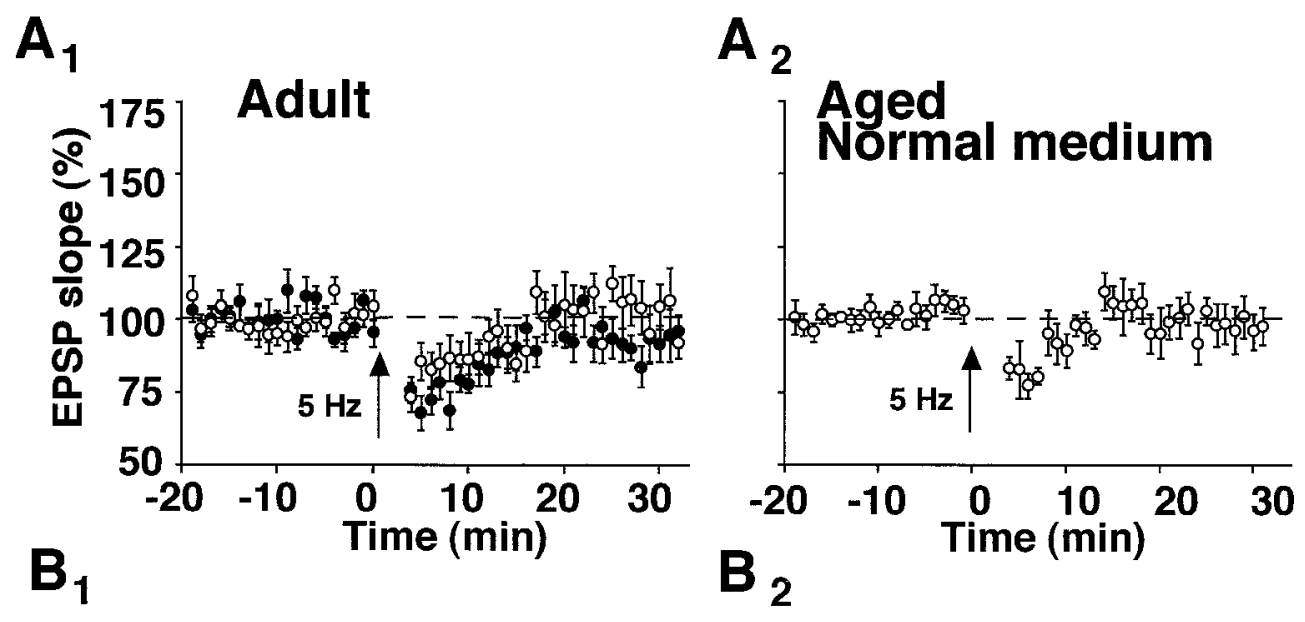

Figure 2. Induction of synaptic modification by $5 \mathrm{~Hz}$ stimulation is a function of age, status of L-channel function, and synaptic strength. $A_{1}$, Slices from adult rats displayed little change in the synaptic response after $5 \mathrm{~Hz}$ stimulation (arrow, 900 pulses), whether they were incubated in normal medium (open circles, $n=6$ ) or in nifedipinecontaining medium ( filled circles, $n=$ 7). $A_{2}$, Similarly, $5 \mathrm{~Hz}$ stimulation delivered to aged rat slices $(n=5)$ bathed in normal perfusion medium also failed to modify synaptic strength. $B_{1}$, In contrast, aged rat slices perfused with nifedipine exhibited a robust synaptic enhancement after $5 \mathrm{~Hz}$ stimulation $(5 \mathrm{~Hz}$ 1) to the test pathway ( filled circles, $n=$ 16). Altered synaptic strength was not observed in the control pathways that did not receive $5 \mathrm{~Hz}$ stimulation (open circles, $n=14$ ). $B_{2}$, For four of the slices illustrated in $B_{1}$, nifedipine was washed from the perfusion medium, and a second round of $5 \mathrm{~Hz}$ stimulation $(5 \mathrm{~Hz} 2)$ was administered. In drug-free medium, depression of the enhanced response, attributable to $5 \mathrm{~Hz}$ stimulation, was obtained. Values plotted in $B_{2}$ were normalized to the average of responses collected during the final 10 min of drug washout (i.e., the last 10 min of recording in $\left.B_{1}\right)$. $C$, Shown are averaged waveforms (from 10 successive sweeps) collected from typical experiments in which $5 \mathrm{~Hz}$ stimulation was administered to slices bathed in nifedipine-containing medium. Arrowheads point to sweeps collected $25-30$ min after the delivery of $5 \mathrm{~Hz}$ stimulation. Sweeps without arrowheads were collected during the $5 \mathrm{~min}$ immediately preceding the $5 \mathrm{~Hz}$ episode. Calibration: $1 \mathrm{mV}, 5 \mathrm{msec}$.
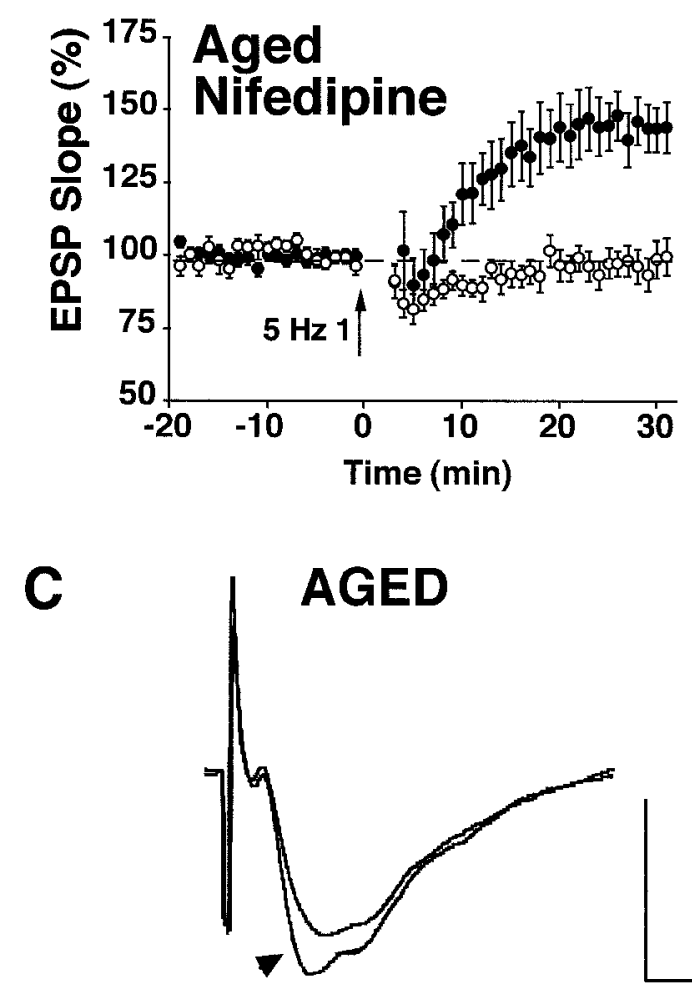

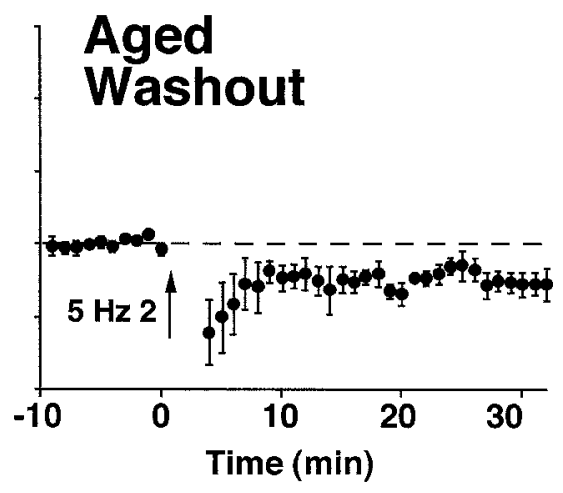

ADULT

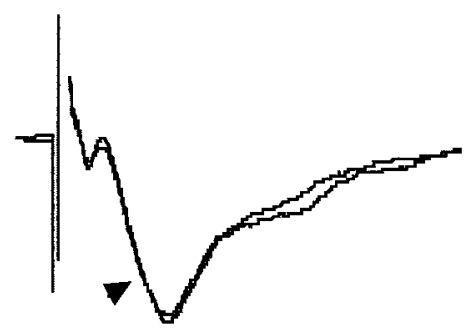

blockade partially occludes conventional LTP, it may not fully saturate the available LTP mechanisms. In other slices from aged rats (Fig. 3B) LTP was induced first in S1, using $100 \mathrm{~Hz}$ stimulation. Immediately after LTP induction $(153 \pm 12 \%, n=5)$, nifedipine was applied to the recording medium, and $5 \mathrm{~Hz}$ stimulation was delivered to the potentiated synapses 30 min later. The $5 \mathrm{~Hz}$ train resulted in no further increase in the synaptic response $(101 \pm 4 \%$ of the post-100 Hz baseline). This lack of further enhancement after the $5 \mathrm{~Hz}$ train was not attributable to a nonspecific change in slice viability, because an additional round of $5 \mathrm{~Hz}$ stimulation delivered to a second, naive group of synapses (S2) in the continued presence of nifedipine produced marked enhancement $(128 \pm 7 \%)$. The results indicate that, in aged rat slices, nifedipine-facilitated enhancement shares mechanisms in common with LTP that is induced by high-frequency stimulation.

The induction of conventional LTP requires postsynaptic influx of $\mathrm{Ca}^{2+}$ via NMDARs (Bliss and Collingridge, 1993). The role of the NMDAR in nifedipine-facilitated enhancement was investigated in aged rats by delivering $5 \mathrm{~Hz}$ stimulation in the combined presence of nifedipine and the NMDAR antagonist AP5 or in the presence of AP5 alone (Fig. 4). Enhancement induced by $5 \mathrm{~Hz}$ stimulation during bath application of nifedipine was blocked by the addition of AP5 to the recording medium $(106 \pm 7 \%, n=5)$ (Fig. 4A). Moreover, no change in synaptic strength was observed when $5 \mathrm{~Hz}$ stimulation was delivered in the presence of AP5 alone $(97 \pm 7 \%, n=4)$ (Fig. $4 B)$, suggesting that synaptic enhancement after $5 \mathrm{~Hz}$ stimulation is specific to the blockade of L-channels and not to the blockade of other voltage-dependent $\mathrm{Ca}^{2+}$ channels, such as the NMDAR. Together, the results demonstrate that nifedipine facilitates the induction of NMDARdependent LTP in aged rats.

\section{Blockade of L-channels does not enhance basal NMDAR function}

One possible mechanism by which nifedipine could facilitate induction of LTP is via a reduction in $\mathrm{Ca}^{2+}$-dependent protein phosphatase activity, which normally downregulates NMDAR function (Lieberman and Mody, 1994; Wang and Salter, 1994; 


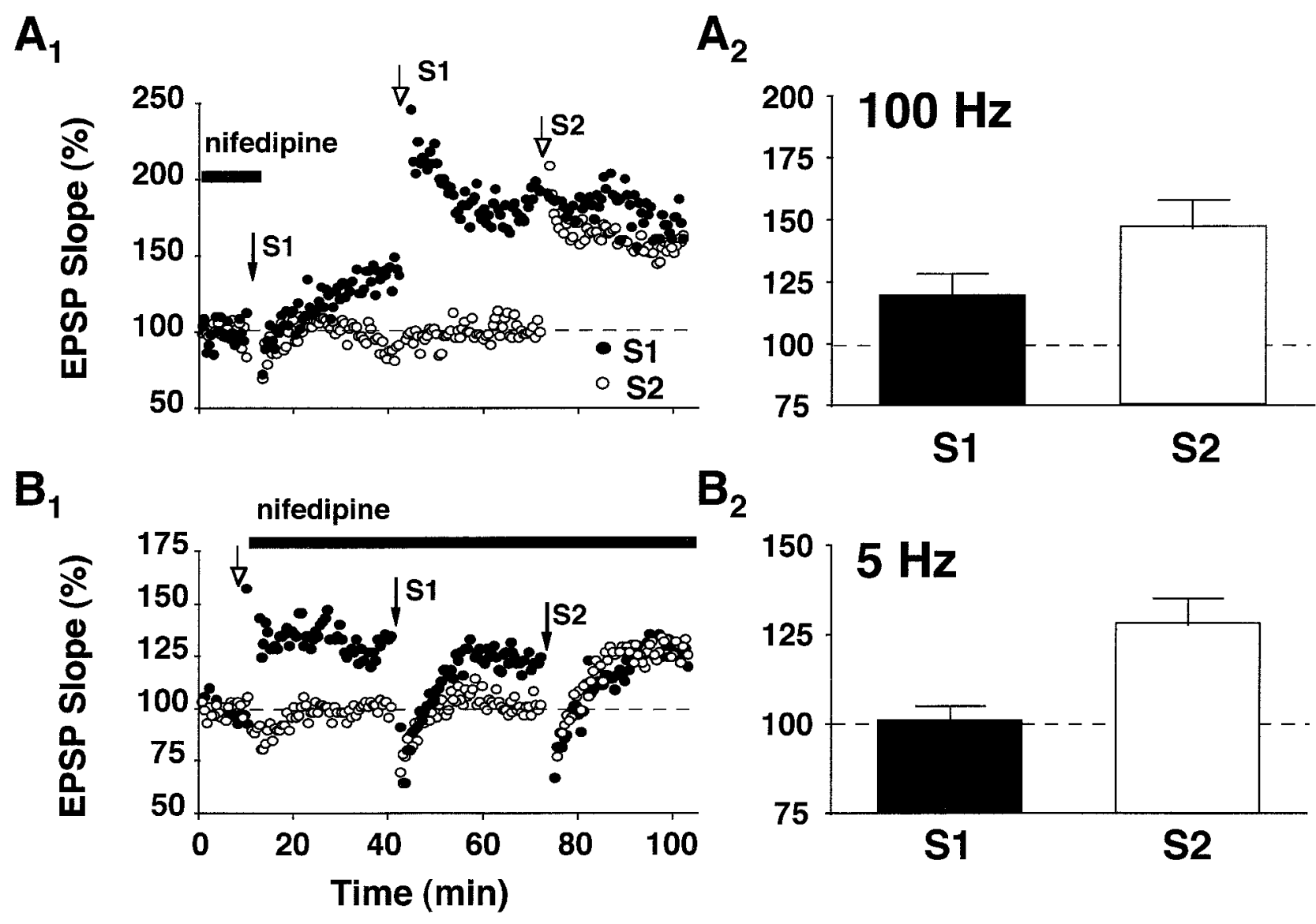

Figure 3. Synaptic enhancement induced by $5 \mathrm{~Hz}$ stimulation during L-channel blockade is mechanistically similar to LTP induced by high-frequency stimulation. $A_{1}$, Experiment conducted on an individual aged rat slice in which synaptic enhancement was first induced in one population of synapses (S1, filled arrow), using $5 \mathrm{~Hz}$ stimulation in the presence of nifedipine. After the $5 \mathrm{~Hz}$ episode, nifedipine was washed from the recording medium, and two bursts of $100 \mathrm{~Hz}$ stimulation were delivered to S1 (open arrow, S1). Approximately 30 min later, a second round of $100 \mathrm{~Hz}$ stimulation was delivered to naive synapses in a second input (open arrow, S2). $A_{2}$, Average data from three aged rat slices in which induction of synaptic enhancement by $5 \mathrm{~Hz}$ stimulation preceded the induction of LTP by $100 \mathrm{~Hz}$ stimulation. Note that, although $100 \mathrm{~Hz}$ stimulation produced further potentiation in S1, the percentage of increase in the synaptic response was much less than the increase observed at naive synapses (i.e., $S 2)$ after $100 \mathrm{~Hz}$ stimulation. $B_{1}$, For an individual aged rat slice, LTP was induced in one pathway (open arrow, S1), using $100 \mathrm{~Hz}$ stimulation. After induction of LTP, nifedipine was washed into the recording medium, and a round of $5 \mathrm{~Hz}$ stimulation was applied to the potentiated synapses (closed arrow, S1). At 30 min after the first round of $5 \mathrm{~Hz}$ stimulation, a second $5 \mathrm{~Hz}$ train was applied to nonpotentiated synapses $(S 2)$ in the continued presence of nifedipine. $B_{2}$, Average data from five aged rat slices in which induction of LTP by $100 \mathrm{~Hz}$ stimulation preceded the induction of synaptic enhancement by $5 \mathrm{~Hz}$ stimulation. Note that, after the induction of LTP in S1, $5 \mathrm{~Hz}$ stimulation in the presence of nifedipine fails to induce synaptic enhancement. However, $5 \mathrm{~Hz}$ stimulation applied to nonpotentiated synapses in S2 produces robust enhancement. Error bars indicate SEM.

Wang et al., 1994). To isolate the NMDAR component of the CA3/CA1 synaptic response, we monitored extracellular EPSPs in slices from aged rats during the wash-in of ACSF, which contained $0.5 \mathrm{~mm} \mathrm{MgSO}_{4}, 20-60 \mu \mathrm{M} \mathrm{DNQX}$, and $10 \mu \mathrm{M}$ picrotoxin. After stabilization of the field EPSP, intracellular recordings were obtained and baseline stimulation $(0.1 \mathrm{~Hz})$ was initiated. Nifedipine was applied to the recording medium $\sim 10 \mathrm{~min}$ later. Figure 5 illustrates that L-channel blockade did not alter the intracellular EPSP area $(93 \pm 5 \%, n=5)$ measured 25-30 min after nifedipine application. However, subsequent application of AP5 $(100 \mu \mathrm{M})$ dramatically reduced the EPSP $(15 \pm 5 \%, n=4)$, demonstrating successful isolation of the NMDAR component of synaptic transmission. The results suggest that nifedipine does not facilitate the induction of LTP in aged rat slices by increasing basal NMDAR-mediated currents.

\section{Nifedipine facilitates LTP by reducing the $\mathrm{Ca}^{2+}$-dependent AHP}

Another way that nifedipine could facilitate synaptic enhancement is via a reduction in the $\mathrm{Ca}^{2+}$-dependent $\mathrm{K}^{+}$-mediated
AHP, which normally is augmented in area CA1 during aging (Landfield and Pitler, 1984; Moyer et al., 1992). Indeed, previous research demonstrates that the AHP can shunt synaptic depolarization in stratum radiatum and impair the induction of LTP by using "weak" stimulation parameters (Sah and Bekkers, 1996). Similar to previous research, intracellular recordings from CA1 cells of aged rats demonstrated that the AHP $(7.4 \pm 2 \mathrm{mV})$ associated with a burst of six to seven action potentials was reduced by $\sim 30 \%(n=5)$ after the addition of nifedipine to the recording medium (Moyer et al., 1992). Drug effects on the AHP were rapid ( $<15 \mathrm{~min}$ after wash-in) and were not associated with a change in the field EPSP (Fig. $6 B_{1}$ ). If nifedipine facilitates synaptic enhancement via a reduction of the AHP, then other compounds that reduce the AHP should have similar effects on synaptic enhancement. Apamin, a peptide that directly blocks $\mathrm{K}^{+}$ channels, reduced the AHP $(4.4 \pm .8 \mathrm{mV})$ in aged rat slices to an extent similar to that of nifedipine (i.e., by $\sim 30 \%, n=5$ ) and did not alter the baseline field EPSP slope (Fig. $6 B_{2}$ ). Also comparable to nifedipine, apamin facilitated the induction of synaptic 
A

B
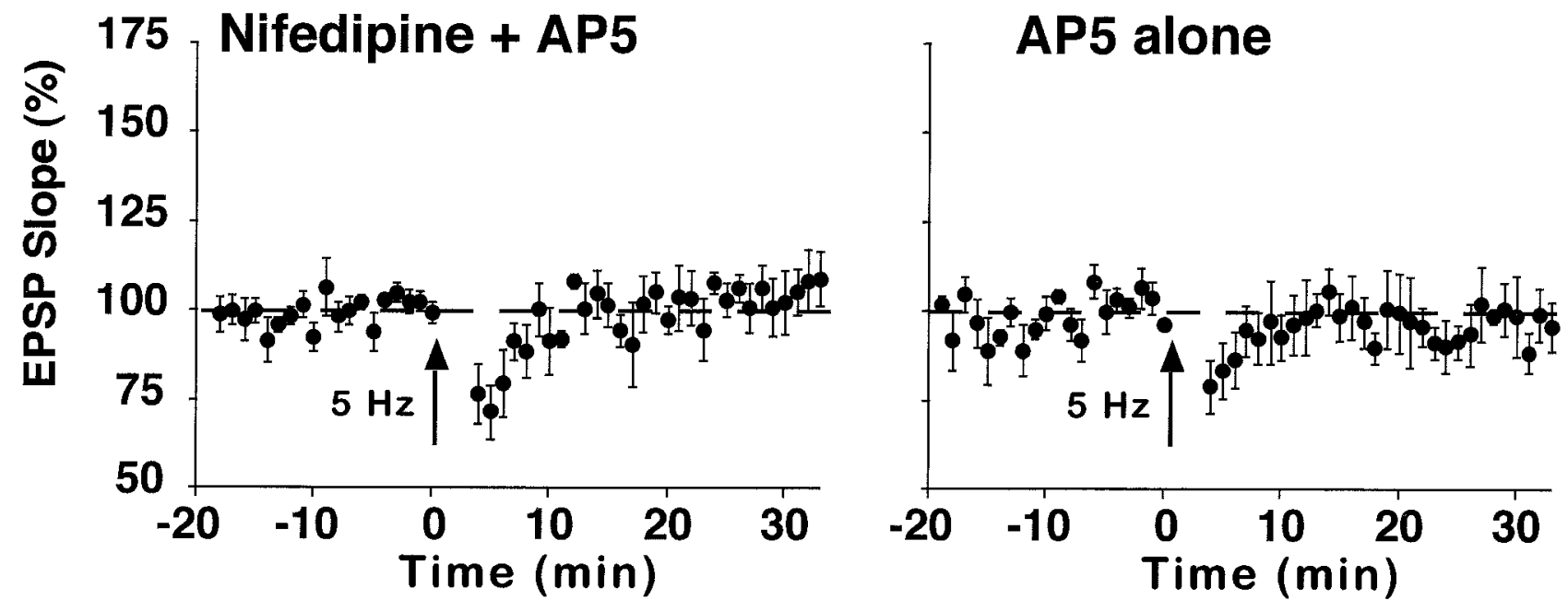

Figure 4. Synaptic enhancement induced by $5 \mathrm{~Hz}$ stimulation is sensitive to AP5. $A$, Aged rat slices $(n=5)$ that were coincubated with nifedipine and AP5 $(100 \mu \mathrm{M})$ did not exhibit synaptic enhancement after a $5 \mathrm{~Hz}$ stimulus train. $B$, Similarly, $5 \mathrm{~Hz}$ stimulation failed to increase synaptic strength when aged rat slices $(n=4)$ were bathed in AP5 alone.

enhancement in aged rats when $5 \mathrm{~Hz}$ stimulation was used (128 \pm $7 \%, n=7$ ) (Fig. $6 C_{1}$ ). However, in contrast to nifedipine, apamin did not prevent the induction of LTD by $1 \mathrm{~Hz}$ stimulation ( $84 \pm$

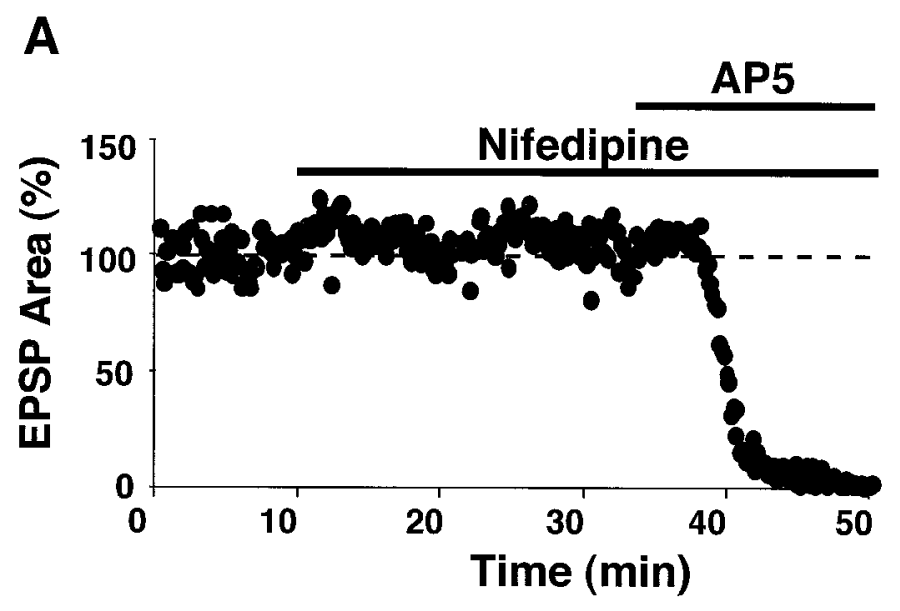

B
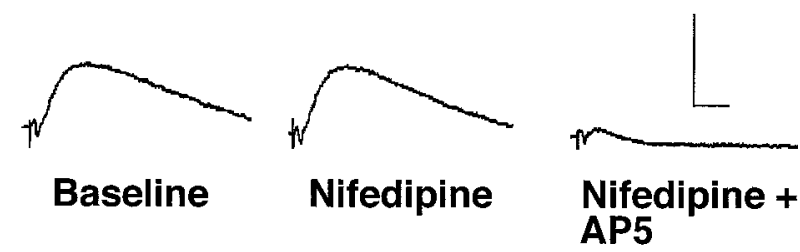

Figure 5. Nifedipine does not alter basal NMDAR-mediated responses. $A$, Plot of intracellular EPSPs (area above baseline) from an individual aged rat slice in response to stimulation of Schaffer collateral fibers $(0.1 \mathrm{~Hz})$. In this experiment the slice was incubated in DNQX $(20 \mu \mathrm{M})$, picrotoxin $(10 \mu \mathrm{M})$, and low extracellular $\mathrm{Mg}^{2+}(0.5 \mathrm{mM})$ to isolate the NMDAR component of CA3/CA1 synaptic transmission. After an initial $10 \mathrm{~min}$ baseline, nifedipine was applied to the slice and did not alter the EPSP. Subsequent application of AP5 $(100 \mu \mathrm{M})$ dramatically reduced the EPSP, demonstrating successful isolation of the NMDAR component of synaptic transmission. $B$, Average intracellular EPSP waveforms generated from 10 successive responses collected during the initial baseline, $30 \mathrm{~min}$ after application of nifedipine, and $15 \mathrm{~min}$ after the addition of AP5. Calibration: $5 \mathrm{mV}, 10 \mathrm{msec}$.
$6 \%, n=7$ ) (Fig. $6 C_{2}$ ). These data indicate that, in slices from aged rats, the AHP may impair LTP induction without dramatically affecting LTD.

\section{DISCUSSION}

The major conclusion of the current study is that, in slices from aged rats, L-channels can (1) facilitate LTD induction during low rates of synaptic activity and (2) impair LTP induction during higher levels of synaptic activation via an increase in the $\mathrm{Ca}^{2+}$ dependent AHP. These findings provide a direct link between a major hypothesis of brain aging, impaired regulation of $\mathrm{Ca}^{2+}$ homeostasis, and alterations in long-lasting $\mathrm{Ca}^{2+}$-dependent synaptic plasticity during aging.

\section{L-channel blockade reverses increased susceptibility to LTD during aging}

Although the induction of LTD in area CA1 often depends on the activation of NMDARs, it is becoming increasingly clear that, under certain conditions, L-channels also contribute to the induction process. For instance, although LTD induction in immature animals usually is blocked by NMDAR antagonists (Bear and Abraham, 1996), other investigators have observed substantial LTD during NMDAR blockade or the inhibition of LTD in the presence of L-channel antagonists (Velisek et al., 1993; Bolshakov and Siegelbaum, 1994; Christie et al., 1996, 1997; Cummings et al., 1996; Goda and Stevens, 1996) (but see Selig et al., 1995). Because LTD induction depends on a modest rise of cytosolic $\mathrm{Ca}^{2+}$ (Bear, 1995), elevated $\mathrm{Ca}^{2+}$ influx through L-channels may lower the rate of synaptic activity that is necessary to increase cytosolic $\mathrm{Ca}^{2+}$ beyond the LTD threshold (Debanne et al., 1994; Foster and Norris, 1997). Consistent with this idea, manipulations that increase $\mathrm{Ca}^{2+}$ influx through L-channels lower the stimulation threshold for LTD induction in adults. Thus, $1 \mathrm{~Hz}$ stimulation that elicits little-to-no LTD in adults produces robust LTD when it is delivered in the presence of Bay K 8644, an L-channel activator (Coussens et al., 1997). Additionally, glucocorticoid receptor activation, which enhances L-channel currents (Kerr et al., 1992), also facilitates LTD in adult animals 
A

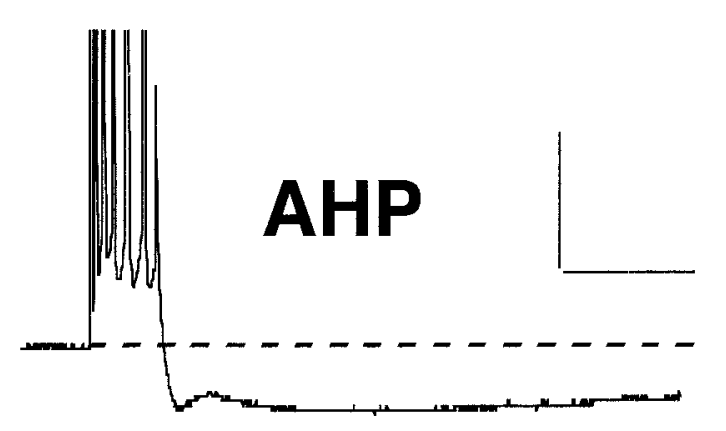

$\mathrm{C}_{1}$

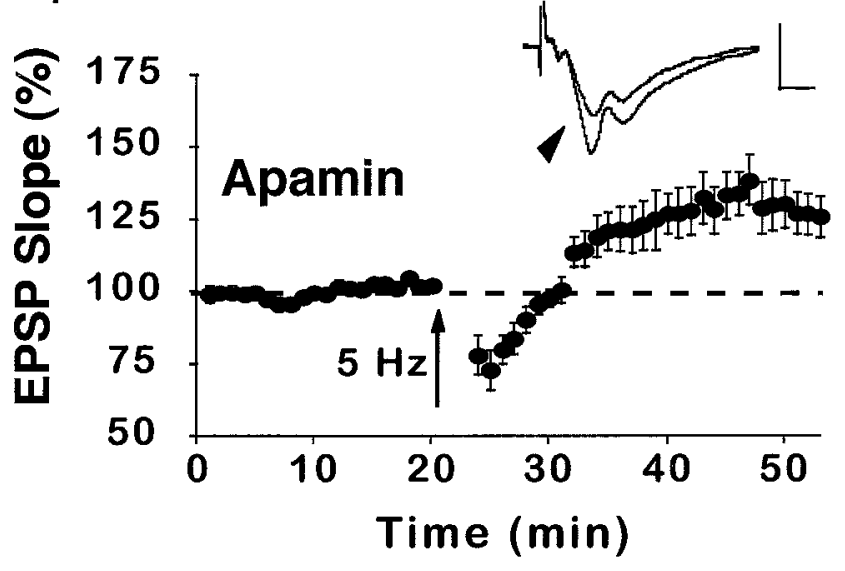

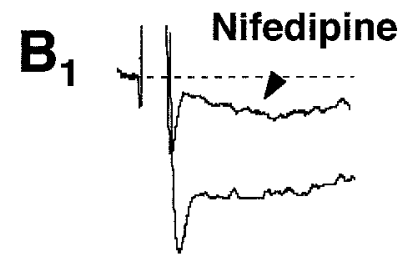

$\mathrm{B}_{2}$
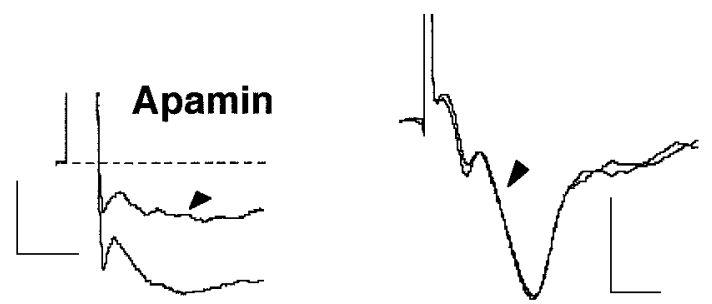

$\mathrm{C}_{2}$

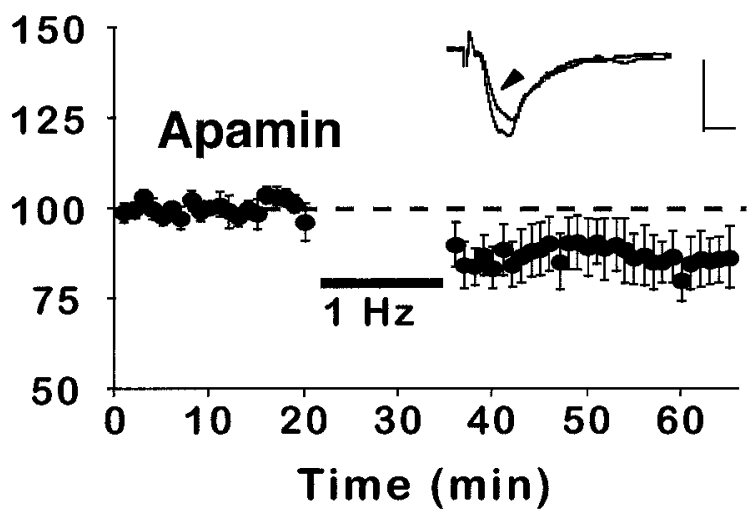

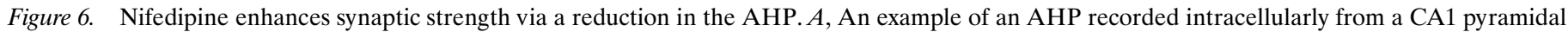

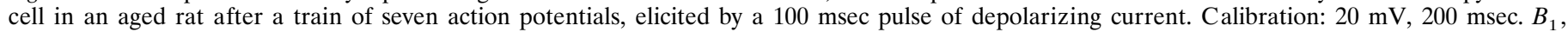

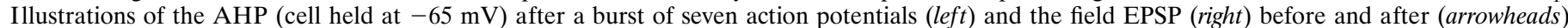

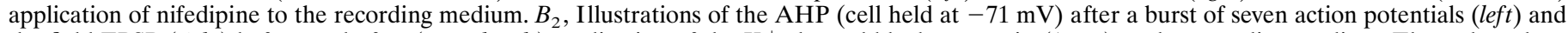

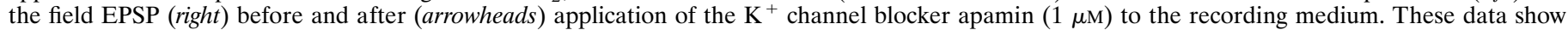

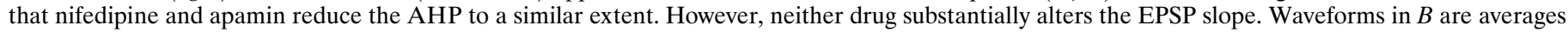

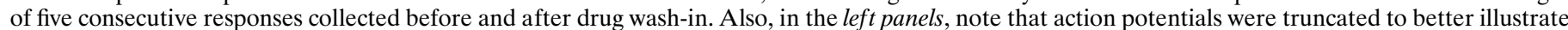

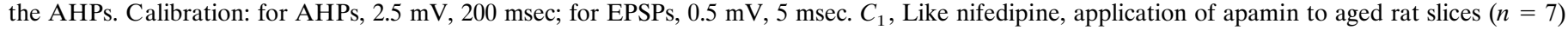

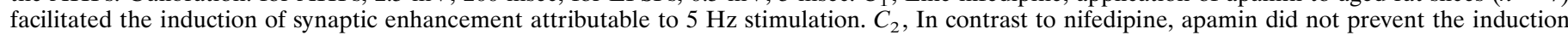

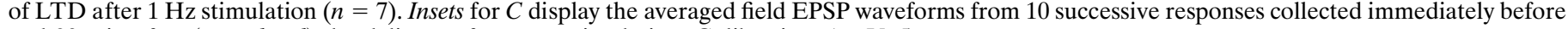
and $30 \mathrm{~min}$ after (arrowhead) the delivery of pattern stimulation. Calibration: $1 \mathrm{mV}, 5 \mathrm{msec}$.

(Kerr et al., 1994, 1996), and this LTD is inhibited by L-channel blockade (Kerr et al., 1996; Coussens et al., 1997). Finally, discrepancies across laboratories in the ability to induce LTD in adults may be linked to the level of extracellular $\mathrm{Ca}^{2+}$ used in the experimental paradigm, which in turn can influence $\mathrm{Ca}^{2+}$ influx during low-frequency stimulation (for a discussion, see Norris et al., 1996).

Relative to young adult rats, aged rats exhibit an increased influx of $\mathrm{Ca}^{2+}$ through L-channels (Campbell et al., 1996; Thibault and Landfield, 1996) as well as an enhanced susceptibility to LTD induction using $1 \mathrm{~Hz}$ stimulation (Norris et al., 1996; Foster and Norris, 1997). Although induction of LTD in aged rats is inhibited by AP5, it is not fully suppressed, implicating an NMDAR-independent component of LTD (Norris et al., 1996). In the present study LTD induced by $1 \mathrm{~Hz}$ stimulation was blocked completely in aged rats by nifedipine, demonstrating that L-channels make a major contribution to LTD induction during aging. Taken together, the results suggest that it is the elevated
$\mathrm{Ca}^{2+}$ influx through L-channels that underlies increased susceptibility to LTD during aging.

\section{L-channel blockade facilitates LTP induction during aging}

In addition to LTD, L-channels also have been implicated in LTP, particularly when very intense stimulation $(>200 \mathrm{~Hz})$ trains are used for induction (Grover and Teyler, 1990, 1995). Thus, increased $\mathrm{Ca}^{2+}$ influx through L-channels during aging may be expected to reduce the stimulation threshold for LTP induction. The results of the current study and previous work, however, are at odds with this prediction (Deupree et al., 1993; Moore et al., 1993; Rosenzweig et al., 1997). In the present study the facilitation of synaptic enhancement in aged rats by using $5 \mathrm{~Hz}$ stimulation only occurred during L-channel blockade. This enhancement was NMDAR-dependent and shared mechanisms in common with conventional LTP induced by $100 \mathrm{~Hz}$ stimulation, as indicated by occlusion experiments. 
Although the facilitation of a $\mathrm{Ca}^{2+}$-dependent process via the blockade of $\mathrm{Ca}^{2+}$ influx appears paradoxical, there are several plausible explanations for this effect. For instance, increased influx of $\mathrm{Ca}^{2+}$ through L-channels may activate intracellular signaling pathways that downregulate NMDAR function (Lieberman and Mody, 1994; Wang and Salter, 1994; Wang et al., 1994) such that, during aging, NMDAR currents normally are depressed. If this scenario is true, then blockade of L-channels would be expected to increase basal NMDAR-mediated responses. However, in the current study L-channel blockade had no significant effects on the NMDAR-mediated component of synaptic transmission in aged rats. Another possibility is that nifedipine facilitates LTP by reducing the $\mathrm{Ca}^{2+}$-dependent $\mathrm{K}^{+}$mediated AHP, which normally is augmented in CA1 cells of aged rodents (Landfield and Pitler, 1984; Moyer et al., 1992). Sah and Bekkers (1996) demonstrated that the AHP in CA1 can shunt synaptic depolarization in stratum radiatum. They suggested that voltage-dependent processes, such as NMDAR activation, may be particularly sensitive to the AHP. Thus, a weak stimulus train that elicited only short-term potentiation induced robust LTP when delivered during pharmacological reduction of the AHP.

Because the AHP is augmented during aging, synaptic activity occurring within the temporal boundaries of the AHP (i.e., activity $>1-2 \mathrm{~Hz}$ ) likely will be affected to a greater extent in aged animals. In the current study two drugs that reduce the AHP (i.e., nifedipine and apamin) facilitated the induction of LTP in aged rats, using $5 \mathrm{~Hz}$ stimulation. Although the level of postsynaptic depolarization was not monitored directly during pattern stimulation trains, the conclusion that LTP is facilitated in aged rats via a reduction in the AHP is supported by the fact that nifedipine and apamin affect the AHP via disparate mechanisms. Specifically, blockade of L-channels reduces the AHP in aged animals by removing a major source of $\mathrm{Ca}^{2+}$ responsible for activating $\mathrm{Ca}^{2+}$-dependent $\mathrm{K}^{+}$channels (Sah, 1996). Apamin, on the other hand, is a peptide that directly blocks the $\mathrm{K}^{+}$channels that mediate the AHP, especially the early component of the AHP (Pineda et al., 1992; Zhang and McBain, 1995; Oh et al., 1997) (but see Lancaster and Nicoll, 1987). Moreover, the fact that apamin did not prevent the induction of LTD by $1 \mathrm{~Hz}$ stimulation suggests that differences in LTD induction between aged and young adult rats likely are not attributable to an age-related increase in the AHP.

In previous research LTP induction deficits at CA3/CA1 synapses were observed in aged animals, using "weak" stimulation parameters (Deupree et al., 1993; Moore et al., 1993; Rosenzweig et al., 1997). In these cases the intensity of the LTP-inducing stimulus was lowered by reducing the duration of the stimulus train. Our data suggest that these LTP deficits may be attributable to an age-related increase in the AHP. Indeed, short-duration trains for inducing LTP (i.e., $<200 \mathrm{msec}$ ) may be especially vulnerable, because a majority of the stimulus pulses are delivered across a period at which the AHP should be at or near its maximum amplitude (Landfield and Pitler, 1984; Moyer et al., 1992). Thus, it would be instructive if future research investigated the effects of L-channel blockade on LTP induction, using the short-duration stimulation paradigms of Deupree et al. (1993) and Moore et al. (1993).

\section{L-channels, synaptic plasticity, and cognition}

Synaptic plasticity mechanisms, both for increasing and decreasing synaptic efficacy, likely interact to regulate synaptic function (Mayford et al., 1995; Hrabetva and Sacktor, 1996; Oliet et al.,
1996, 1997; Foster et al., 1997). By facilitating and inhibiting LTD and LTP induction, respectively, the overall effect of increased L-channel activity during aging would favor the weakening of synaptic efficacy (Foster and Norris, 1997), which is a primary electrophysiological marker for age-related cognitive deficits (Barnes et al., 1992, 1996). Thus, the current study provides a plausible mechanistic link between age-related memory deficits and L-channel activity in the aging brain (Deyo et al., 1989; Straube et al., 1990; Levere and Walker, 1992; Ingram et al., 1994; Kowalska and Disterhoft, 1994; Soloman et al., 1995; Thibault and Landfield, 1996). Moreover, the results continue to support the examination of L-channel blockers in the early therapeutic intervention of age-related neurodegenerative diseases such as Alzheimer's (Fischhof, 1993; Grobe-Einsler, 1993; Parnetti et al., 1993; Fritze and Walden, 1995).

\section{REFERENCES}

Barnes CA, McNaughton BL (1980) Spatial memory and hippocampal synaptic plasticity in senescent and middle-aged rats. In: The psychobiology of aging: problems and perspectives (Stein D, ed), pp 253-272. Amsterdam: Elsevier.

Barnes CA, Rao G, Foster TC, McNaughton BL (1992) Region-specific age effects on AMPA sensitivity: electrophysiological evidence for loss of synaptic contacts in hippocampal field CA1. Hippocampus 2:457-468.

Barnes CA, Rao G, McNaughton BL (1996) Functional integrity of NMDA-dependent LTP induction mechanisms across the lifespan of F-344 rats. Learn Memory 3:124-137.

Bear MF (1995) Mechanism for a sliding synaptic modification threshold. Neuron 15:1-4.

Bear MF, Abraham WC (1996) Long-term depression in hippocampus. Annu Rev Neurosci 19:437-462.

Bliss TVP, Collingridge GL (1993) A synaptic model of memory: longterm potentiation in the hippocampus. Nature 361:31-39.

Bolshakov VY, Siegelbaum SA (1994) Postsynaptic induction and presynaptic expression of hippocampal long-term depression. Science 264:1148-1152.

Campbell LW, Hao SY, Thibault O, Blalock EM, Landfield PW (1996) Aging changes in voltage-gated calcium currents in hippocampal CA1 neurons. J Neurosci 16:6286-6295.

Christie BR, Magee JC, Johnston D (1996) The role of dendritic action potentials and $\mathrm{Ca}^{2+}$ influx in the induction of homosynaptic long-term depression in hippocampal CA1 pyramidal neurons. Learn Memory 3:160-169.

Christie BR, Schexnayder LK, Johnson D (1997) Contribution of voltage-gated $\mathrm{Ca}^{2+}$ channels to homosynaptic long-term depression in the CA1 region in vitro. J Neurophysiol 77:1651-1655.

Coussens CM, Kerr DS, Abraham WC (1997) Glucocorticoid receptor activation lowers the threshold for NMDA receptor-dependent homosynaptic long-term depression in the hippocampus through activation of voltage-dependent Ca channels. J Neurophysiol 78:1-9.

Cummings JA, Mulkey RM, Nicoll RA, Malenka RC (1996) $\mathrm{CA}^{2+}$ signaling requirements for long-term depression in the hippocampus. Neuron 16:825-833.

Debanne D, Gähwiler BH, Thompson SM (1994) Asynchronous preand postsynaptic activity induces associative long-term depression in CA1 of the rat hippocampus in vitro. Proc Natl Acad Sci USA 19:1148-1152.

deToledo-Morrell L, Geinisman Y, Morrell F (1988) Age-dependent alterations In hippocampal synaptic plasticity: relation to memory disorders. Neurobiol Aging 9:581-590.

Deupree DL, Bradley J, Turner DA (1993) Age-related alterations in potentiation in the CA1 region in F-344 rats. Neurobiol Aging $14: 249-258$

Deyo RA, Straube KT, Disterhoft JF (1989) Nimodipine facilitates trace conditioning of the eyeblink response in aging rabbits. Science 243:809-811.

Fischhof PK (1993) Divergent neuroprotective effects of nimodipine in PDD and MID provide indirect evidence of disturbances in $\mathrm{Ca}^{2+}$ homeostasis in dementia. Methods Find Exp Clin Pharmacol 15:549-555.

Foster TC, Norris CM (1997) Age-associated changes in $\mathrm{Ca}^{2+}$ 
dependent processes: relation to hippocampal synaptic plasticity. Hippocampus 7:602-612.

Foster TC, Norris CM, Halpain S (1997) Protein phosphatase inhibition enhances CA1 synaptic responses in aged, but not adult rats. Soc Neurosci Abstr 23:263.15.

Fritze J, Walden J (1995) Clinical findings with nimodipine in dementia: test of the calcium hypothesis. J Neural Transm 46:439-453.

Goda Y, Stevens CF (1996) Long-term depression properties in a simple system. Neuron 16:103-111.

Grobe-Einsler R (1993) Clinical aspects of nimodipine. Clin Neuropharmacol 16:S39-S45.

Grover LM, Teyler TJ (1990) Two components of long-term potentiation induced by different patterns of afferent activation. Nature 347:477-479.

Grover LM, Teyler TJ (1995) Different mechanisms may be required for maintenance of NMDA receptor-dependent and independent forms of long-term potentiation. Synapse 19:121-133.

Hrabetva S, Sacktor TC (1996) Bidirectional regulation of protein kinase $\mathrm{M} \zeta$ in the maintenance of long-term potentiation and long-term depression. J Neurosci 16:5324-5333.

Ingram DK, Joseph JA, Spangler EL, Roberts D, Hengemihle J, Fanelli RJ (1994) Chronic nimodipine treatment in aged rats: analysis of motor and cognitive effects and muscarinic-induced striatal dopamine release. Neurobiol Aging 15:55-61.

Kerr DS, Campbell LW, Thibault O, Landfield PW (1992) Hippocampal glucocorticoid receptor activation enhances voltage-dependent $\mathrm{Ca}^{2+}$ conductances: relevance to brain aging. Proc Natl Acad Sci USA 89:8527-8531.

Kerr DS, Huggett AM, Abraham WC (1994) Modulation of hippocampal long-term potentiation and long-term depression by corticosteroid receptor activation. Psychobiology 22:123-133.

Kerr DS, Davis PWK, Abraham WC (1996) Enhancement of homosynaptic long-term depression by the type II glucocorticoid receptor agonist RU-28362. Int J Neurosci 84:251.

Kowalska M, Disterhoft JF (1994) Relation of nimodipine dose and serum concentration to learning enhancement in aging rabbits. Exp Neurol 127:159-166.

Lancaster B, Nicoll RA (1987) Properties of two calcium-activated hyperpolarizations in rat hippocampal neurons. J Physiol (Lond) 389:187-203.

Landfield PW, Pitler TA (1984) Prolonged $\mathrm{Ca}^{2+}$-dependent afterhyperpolarizations in hippocampal neurons of aged rats. Science 226:1089-1092.

Landfield PW, Pitler TA, Applegate MD (1986) The effects of high $\mathrm{Mg}^{2+}$-to- $\mathrm{Ca}^{2+}$ ratios on frequency potentiation in hippocampal slices of young and aged rats. J Neurophysiol 56:797-811.

Levere TE, Walker A (1992) Old age and cognition: enhancement of recent memory in aged rats by the calcium channel blocker nimodipine. Neurobiol Aging 13:63-66.

Lieberman DN, Mody I (1994) Regulation of NMDA channel function by endogenous $\mathrm{Ca}^{2+}$-dependent phosphatase. Nature 369:235-239.

Mayford M, Wang J, Kandel ER, O'Dell TJ (1995) CaMK-II regulates the frequency-response function of hippocampal synapses for the production of both LTD and LTP. Cell 81:891-904.

Moore CI, Browning MD, Rose GM (1993) Hippocampal plasticity induced by primed burst, but not long-term potentiation, stimulation is impaired in area CA1 of aged Fischer 344 rats. Hippocampus 3:57-66.

Moyer JR, Disterhoft JF (1994) Nimodipine decreases calcium action potentials in rabbit hippocampal CA1 neurons in an age-dependent and concentration-dependent manner. Hippocampus 4:11-18.

Moyer JR, Thompson LT, Black JP, Disterhoft JF (1992) Nimodipine increases excitability of rabbit CA1 pyramidal neurons in an age- and concentration-dependent manner. J Neurophysiol 68:2100-2109.

Mulkey RM, Malenka RC (1992) Mechanisms underlying induction of homosynaptic long-term depression in area CA1 of the hippocampus. Neuron 9:967-975.

Norris CM, Korol DL, Foster TC (1996) Increased susceptibility to induction of long-term depression and long-term potentiation reversal during aging. J Neurosci 16:5382-5392.

Norris CM, Foster TC, Halpain S (1997) Susceptibility to synaptic modification in the aged rat is dynamically regulated by afferent activity and L-type $\mathrm{Ca}^{2+}$ channel function. Soc Neurosci Abstr 23:263.14.

O'Dell TJ, Kandel ER (1994) Low-frequency stimulation erases LTP through an NMDA receptor-mediated activation of protein phosphatases. Learn Memory 1:129-139.

Oh MM, Power M, Thompson LT, Disterhoft JF (1997) Apamin decreases the afterhyperpolarization in rabbit CA1 neurons. Soc Neurosci Abstr 23:683.2.

Oliet SHR, Malenka RC, Nicoll RA (1996) Bidirectional control of quantal size by synaptic activity in the hippocampus. Science 271:1294-1297.

Oliet SHR, Malenka RC, Nicoll RA (1997) Two distinct forms of longterm depression coexist in CA1 hippocampal pyramidal cells. Neuron 18:969-982.

Parnetti L, Senin U, Carosi M, Baasch H (1993) Mental deterioration in old age: results in two multicenter, clinical trials with nimodipine. Clin Ther 15:394-406.

Pineda JC, Galarraga E, Bargas M, Cristancho M, Aceves J (1992) Charybdotoxin and apamin sensitivity of the calcium-dependent repolarization and afterhyperpolarization in neostriatal neurons. J Neurophysiol 68:287-294.

Pitler TA, Landfield PW (1990) Aging-related prolongation of calcium spike duration in rat hippocampal slice neurons. Brain Res 508:1-6.

Rosenzweig ES, Rao G, McNaughton BL, Barnes CA (1997) Role of temporal summation in age-related long-term potentiation induction deficits. Hippocampus 7:549-558.

Sah P (1996) $\mathrm{Ca}^{2+}$-activated $\mathrm{K}^{+}$currents in neurones: types, physiological roles, and modulation. Trends Neurosci 19:150-154.

Sah P, Bekkers JM (1996) Apical dendritic location of slow afterhyperpolarization current in hippocampal pyramidal neurons: implications for the integration of long-term potentiation. J Neurosci 16:4537-4542.

Selig DK, Lee HK, Bear MF, Malenka RC (1995) Reexamination of the effects of MCPG on hippocampal LTP, LTD, and depotentiation. J Neurophysiol 74:1075-1082.

Soloman PR, Wood MS, Groccia-Ellison ME, Yang BY, Fanelli RJ, Mervis RF (1995) Nimodipine facilitates retention of the classically conditioned nictitating membrane response in aged rabbits over long retention intervals. Neurobiol Aging 16:791-796.

Staubli U, Lynch G (1990) Stable depression of potentiated synaptic responses in the hippocampus with $1-5 \mathrm{~Hz}$ stimulation. Brain Res 513:113-118.

Straube KT, Deyo RA, Moyer Jr JR, Disterhoft JF (1990) Dietary nimodipine improves associative learning in aging rabbits. Neurobiol Aging 11:659-661.

Thibault O, Landfield PW (1996) Increase in single L-type calcium channels in hippocampal neurons during aging. Science 272:1017-1020.

Velisek L, Moshe SL, Stanton PK (1993) Age dependence of homosynaptic non-NMDA-mediated long-term depression in field CA1 of rat hippocampal slices. Dev Brain Res 75:253-260.

Wang LY, Orser BA, Brautigan DL, MacDonald JF (1994) Regulation of NMDA receptors in cultured hippocampal neurons by protein phosphatases 1 and 2A. Nature 369:230-232.

Wang YT, Salter MW (1994) Regulation of NMDA receptors by tyrosine kinases and phosphatases. Nature 369:233-235.

Zhang L, McBain CJ (1995) Potassium conductances underlying repolarization and after-hyperpolarization in rat CA1 hippocampal interneurones. J Physiol (Lond) 488:661-672. 